\title{
Optimality in Inventory and Machinery Replacement Models
}

\author{
Rowland Jerry Okechukwu Ekeocha ${ }^{1}$
}

${ }^{1}$ Covenant University, Ota Nigeria

\begin{abstract}
In my first article, optimization of industrial system was achieved by the use of the simultaneous equation method while stochastic approximation was employed in obtaining optimality of the queuing system. In this paper, differential calculus and repeated trials were employed to located the optimum lot size of the inventory model while the optimization, dynamic programming and the economic lot size methods were required to obtain optimality of the replacement/rehabilitation model. If the first article created an impression that optimality is limited to some systems like the industrial and queuing systems the extension of optimality to the inventory and replacement/rehabilitation model shows that optimality is achievable in every system/model provided appropriate optimization technique is employed.
\end{abstract}

Keywords: Optimality, Optimization Technique, Models

\begin{abstract}
Introduction
Optimization is defined as the mathematical procedures involved in effecting optimality. It is also a collection of mathematical principles and methods used for solving quantitative problems in many disciplines. (Merriam Webster). The model of a system is a replica (physical or mathematical) which has all the properties (attributes) and function of the system. According to Singh (2009), formal models can be classified as physical, mathematical and computer models. The physical model is the scaled down model of the actual system which has all its properties. Mathematical models represent a system with mathematical equations while computer models utilize computers to numerically evaluate mathematical models. System and model may be interchanged in this write-up. My first article (Ekeocha, 2019) on optimality focused on optimization of industrial and queuing systems. The extension of optimality to inventory and machinery replacement models indicates that optimality is achievable in virtually every situation provided appropriate optimization technique is employed.
\end{abstract}

\section{Methodology \\ Optimality in inventory and machinery replacement models will be addressed with worked examples employing appropriate optimization technique.}

\section{Inventory Model (Humphreys, 1991)}

This is a stock of physical assets having value which can be material, money or labour. Material inventory can be raw material, tools and accessories including spare parts used in production, unfinished or inprocess inventory and finished products. Inventories are maintained at a cost to gain advantages having monetary value, such as avoiding a shutdown due to a temporary absence of supplies or permitting uniform production for a reasonable supply or demand.

Inventory models which are usually mathematical (sometimes symbols) may be deterministic, for which all information and values are treated as being definite or probabilistic (stochastic), for which uncertainty in some values is recognized and considered.

In the general inventory system, ordinates represent the number of units available in stock against time in the abscissa. Consider quantity $\mathrm{Q}$ units received at the beginning of the period $\mathrm{T}_{1}$. The use during this period $U_{1}$ is subtracted from the stock to give a lower stock for the second period, etc. At the end of the fourth period $T_{4}$ the level of inventory reaches the reorder level $\mathrm{R}$. At that time an order equal to $\mathrm{Q}$ unit is placed, which is eventually received at the beginning of the period. The procurement time or lead time $T_{i}$ is the time required in period to receive an order after it is placed. During the procurement time the level of stock may go to zero, creating a shortage for which a penalty can arise. The objective is to minimize the total cost of the system, which is the minimum cost per period (not per cycle). Some costs are connected with the cycle, such as placing and receiving an order, whereas other costs are connected with a period, such as storage costs. Confusion between a period and a cycle is the most common source of error for a beginner.

This article is published under the terms of the Creative Commons Attribution License 4.0

Author(s) retain the copyright of this article. Publication rights with Alkhaer Publications.

Published at: http://www.ijsciences.com/pub/issue/2019-05/

DOI: 10.18483/ijSci.2053; Online ISSN: 2305-3925; Print ISSN: 2410-4477 


\section{Economic Lot Size}

The following assumptions are made for the simplest case:

- All items are delivered simultaneously at the time the stock becomes zero

- The cost of placing and receiving an order is constant and is independent of the lot size

- Usage is at a constant rate
- No safety stock is provided

- No shortage is allowed

- The warehousing cost is calculated on a continuous basis and at any instant of time is proportional to the number of items in the inventory.

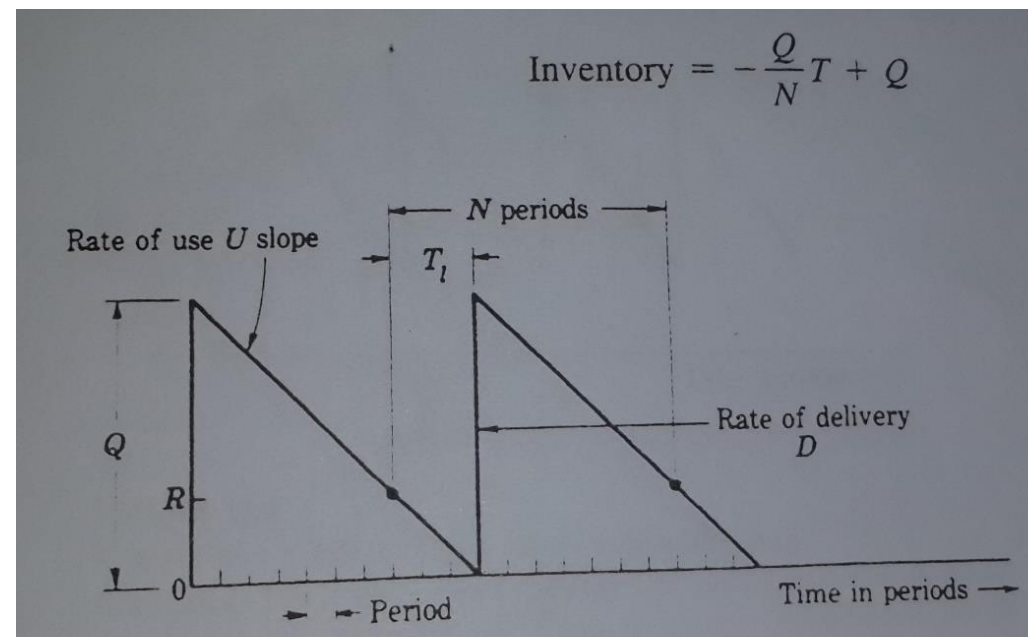

FIGURE 11.3

Diagram for a simpie inventory model

Fig. 11.3 illustrates the schematic diagram for economic lot size. Let $\mathrm{C}_{0}$ be the cost of placing and receiving an order, $C_{h}$ the storage or holding cost per item per period, $\mathrm{M}=\mathrm{Q}$ the maximum inventory where $\mathrm{Q}$ is the lot order, and $\mathrm{U}$ the rate of use in items per period. Consider a time element $\mathrm{T}$ unit of time from zero-time lasting dT units of time. The inventory at any time is a straight-line function of time and is $\mathrm{Q}$ at $\mathrm{T}=0$ and 0 at $\mathrm{T}=\mathrm{N}$ where $\mathrm{N}$ is the duration of the cycle. Then

Inventory $=-\frac{Q}{N} T+Q$

The number of periods of time $\mathrm{N}$ that the lot $\mathrm{Q}$ will last is given by

$\mathrm{N}=\frac{\text { items }}{\text { items } / \text { period }}=\frac{Q}{U}$

The inventory at any time is given by

Inventory $=-\mathrm{UT}+\mathrm{Q}$

The total cycle cost is given by

$$
\mathrm{C}_{\text {cycle }}=\mathrm{C}_{0}+\int_{0}^{N=Q / U} C_{h}(-U T+Q) d T=C_{0}+C_{h}\left(-\frac{U Q^{2}}{2 U^{2}}+Q \frac{Q}{U}\right)
$$

$=\mathrm{C}_{0}+\frac{C_{h} Q^{2}}{2 U}$

The function to be optimized is the cost per period $\mathrm{C}_{\mathrm{t}}$ and with

Cycle $/$ period $=\frac{\text { item } / \text { period }}{\text { item } / \text { cycle }}=\frac{U}{Q}$

The cost per period becomes

$\mathrm{C}_{\mathrm{t}}=\frac{\text { Naira }}{\text { cycle }} \frac{\text { cycle }}{\text { period }}=\left(C_{0}+\frac{C_{h} Q^{2}}{2 U}\right) \frac{U}{Q}=C_{0} \frac{U}{Q}+\frac{C_{h} Q}{2}$

Differentiating and setting to zero, we obtain

$\frac{d C_{t}}{d Q}=-C_{0} \frac{U}{Q^{2}}+\frac{C_{h}}{2}=0$

Finally,

$\mathrm{Q}_{\text {opt. }}=\sqrt{\frac{2 C_{0} U}{C_{h}}}$

The lead time $T_{i}$ multiplied by the rate of use per period $\mathrm{U}$ gives the reorder level, $\mathrm{R}$. Thus

$\mathrm{R}=\mathrm{T}_{\mathrm{i}} \mathrm{U}$

By placing $\mathrm{Q}_{\text {opt. }}$ in $\mathrm{C}_{\mathrm{t}}$, the optimum period cost is obtained, 
$\mathrm{C}_{\mathrm{t}}=C_{0} \frac{U}{\sqrt{2 C_{0} U / C_{h}}}+C_{h} \sqrt{\frac{C_{0} U}{C_{h}}}=\sqrt{2 C_{h} C_{0} U}$

\section{Example:}

The demand for an item 100/day. The cost of placing and receiving an order is \#50 with an infinite delivery rate. The storage cost is \#10 per item per year based on the actual inventory at any time. No shortage is allowed. The reorder level is an 8-day delivery. Find the optimum stock, the optimum period cost and the reorder level.

\section{Solution:}

i. The storage charge per item per day is $10 / 365$ $=0.0274$. Thus, the optimum stock is

$$
\mathrm{Q}_{\text {opt. }}=\sqrt{\frac{2(50)(100)}{0.0274}}=604
$$

ii. The optimum period cost is given by $\mathrm{C}_{\mathrm{t}}=\sqrt{2(0.0274)(50)(100)}=16.55 /$ day

iii. The reorder level is given by $\mathrm{R}=8(100)=800$

\section{Safety Stock:}

This is added to the inventory to ensure that a shortage in an item does not occur. The inventory model becomes

(fig.11.4)



Inventory $=-\mathrm{UT}+\mathrm{Q}+\mathrm{S}(\mathrm{S}=$ Safety Stock $)$

The cost per cycle (following individual steps established previously)

$$
\mathrm{C}_{\text {cycle }}=C_{0}+C_{h}\left(\frac{Q^{2}}{2 U}+S \frac{Q}{U}\right)
$$

The cost per period becomes

$$
\mathrm{C}_{\mathrm{t}}=\mathrm{C}_{0} \frac{U}{Q}+C_{h} \frac{Q}{2}+S C_{h}
$$

The optimum order for minimum cost becomes
$\mathrm{Q}_{\text {opt. }}=\sqrt{\frac{2 C_{0} U}{C_{h}}}$

The optimum period cost becomes

$$
\mathrm{C}_{\mathrm{t}}=\begin{aligned}
& \sqrt{2 C_{h} C_{0} U}+S C_{h} \\
& \sqrt{2 C_{h} C_{0} U}, \text { when, } S=0
\end{aligned}
$$

\section{Finite Rate Delivery}

Finite rate delivery model is associated with manufacturing. 


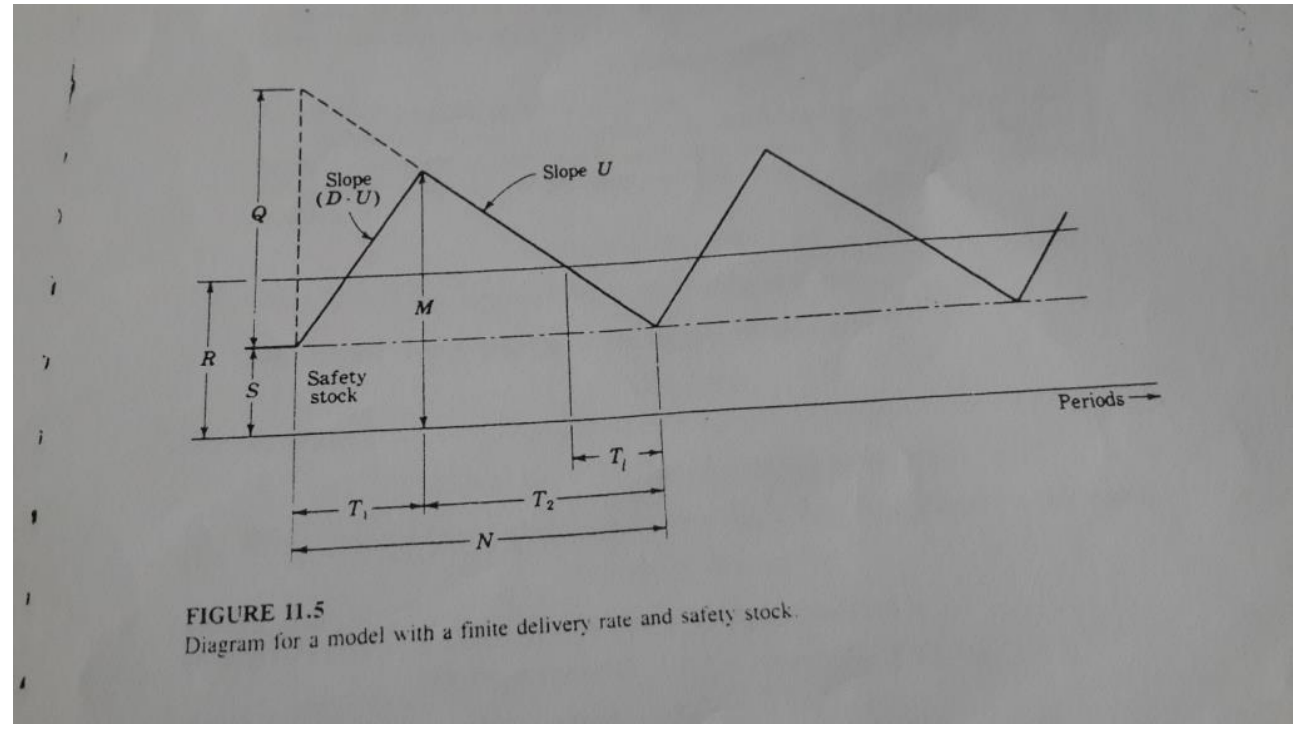

The schematic diagram (fig.11.5) illustrates the model concept. $\mathrm{C}_{0}$ is a setup cost and D item per unit of time is a manufacturing rate. The use rate in items per unit of time is $U$. The value for $Q$ is the total number of items produced and used in the cycle of $\left(T_{1}+T_{2}\right)$ periods. The safety stock is $S$ items and $M$ is the maximum inventory. In time $T_{1}$ the inventory builds up by an amount $(\mathrm{M}-\mathrm{S})$ at a rate $(\mathrm{D}-\mathrm{U})$. Thus

$\mathrm{M}-\mathrm{S}=\mathrm{T}_{1}(\mathrm{D}-\mathrm{U})$ and $\mathrm{Q}=\mathrm{T}_{1} \mathrm{D}($ Since $\mathrm{Q}$ is made at $\mathrm{D}$ rate in time $\left.\mathrm{T}_{1}\right)$

Eliminating $\mathrm{T}_{1}$ gives

$\mathrm{M}-\mathrm{S}=\mathrm{Q} \frac{D-U}{D}$

But $\mathrm{Q}=\mathrm{UN}(\mathrm{Q}$ is used in $\mathrm{N}$ period at $\mathrm{U}$ rate), then

$\mathrm{M}-\mathrm{S}=\mathrm{UN} \frac{D-U}{D}$

In this model $(\mathrm{M}-\mathrm{S})$ is linear with time on both sides of the maximum inventory. The average inventory for the total $\mathrm{N}$ periods is half $(\mathrm{M}-\mathrm{S})$ plus the safety stock.

Average inventory $=\frac{U N}{2} \frac{D-U}{D}+S$

The average inventory is held at a cost $C_{h}$ per item per period. The cost per period is

$\mathrm{C}_{\mathrm{t}}=\left[\mathrm{C}_{0}+\left(\frac{U N}{2} \frac{D-U}{D}+S\right) \mathrm{C}_{\mathrm{h}} \mathrm{N}\right] \frac{\text { naira }}{\text { cycle }} \frac{1}{N} \frac{\text { cycle }}{\text { period }}$

$=\frac{C_{0}}{N}+\frac{U N}{2} \frac{D-U}{D} C_{h}+C_{h} S$

Differentiating, we obtain,

$\frac{d C_{t}}{d N}=\frac{C_{0}}{N^{2}}+\frac{C_{h} U}{2} \frac{D-U}{D}=0$

$$
\mathrm{N}=\sqrt{\frac{2 C_{0} D}{C_{h} U(D-U)}}
$$

Thus, the optimum stock is

$\mathrm{Q}_{\text {opt. }}=\sqrt{\frac{2 C_{0} U D}{C_{h}(D-U)}} \quad($ Since $\mathrm{Q}=\mathrm{UN})$

And the minimum period cost is

$\mathrm{C}_{\mathrm{t}}=\sqrt{\frac{2 C_{h} C_{0} U(D-U)}{D}}+C_{h} S$

\section{Example:}

The setup cost for a small operation is \#600 and the storage cost is \#0.40 per item per day. Usage is uniform at 300 items per day and the production rate is 500 items per day. A safety stock of 100 units is required. Find the optimum production lot size that gives minimum cost.

\section{Solution:}

i. The optimum lot size is given by

$$
\mathrm{Q}_{\text {opt. }}=\sqrt{\frac{2(600)(300)(500)}{(0.40)(500-300)}}=1500
$$

ii. The minimum period cost is given by

$$
\mathrm{C}_{\mathrm{t}}=\sqrt{\frac{2(0.40)(600)(300)(500-300)}{500}}+0.40(100)=280 / \text { day }
$$

iii. The production time is given by

$$
\mathrm{T}_{\mathrm{i}}=\frac{Q}{D}=\frac{1500}{500}=3 \text { days }
$$

iv. The cycle time is given by

$$
\mathrm{N}=\frac{Q}{U}=\frac{1500}{300}=5 \text { days }
$$


Example: (Setting Up Inventory Problem)

The demand of an item is uniform at 1000 items per The cost for placing and receiving an order size is given by

$$
C_{0}=13000+5 Q^{0.5}
$$

It costs \#0.002/day for each item in storage. In addition, there is an antispoilage cost while in storage which is proportional to the age of the inventory multiplied by the number of units in the inventory at the time. If the inventory is 20 days old and there are 8000 items in stock, the antispoilage cost would be day. Delivery when placing an order is immediate.

(0.000015) (20) (8000) \#/day, where 0.000015 is a constant.

Find the optimum lot size.

\section{Solution:}

Let a cycle last $\mathrm{N}$ day. The lot size will then be $\mathrm{Q}=$ $1000 \mathrm{~N}$ and

$C_{0}=13000+5(1000 N)^{0.5}=13000+158.11 N^{0.5}$

The inventory declines linearly from $1000 \mathrm{~N}$ to zero in $\mathrm{N}$ days. The inventory at any time is

Inventory $=1000(\mathrm{~N}-\mathrm{T})$, where $\mathrm{T}$ is in days.

The cost for antispoilage at that time is given by $(0.000015) \mathrm{T}[1000(\mathrm{~N}-\mathrm{T})]=0.015\left(\mathrm{NT}-\mathrm{T}^{2}\right) \# /$ day The cost per cycle $=13000+158.11 \mathrm{~N}^{0.5}+\int_{0}^{N} 0.002[1000(N-T)] d T+\int_{0}^{N} 0.015\left(N T-T^{2}\right) d T$

Integrating, we obtain,

$13000+158.11 \mathrm{~N}^{0.5}+\mathrm{N}^{2}+0.0025 \mathrm{~N}^{3}=13000 \mathrm{~N}^{-1}+158.11 \mathrm{~N}^{-0.5}+\mathrm{N}+0.0025 \mathrm{~N}^{2}=0$

By repeated trails, the minimum occurs at $\mathrm{N}=96.4$

And

for which the optimum lot size

$\mathrm{Q}_{\text {opt. }}=1000 \mathrm{~N}=96400$ items.

\section{Remark}

The inventory model is a differentiable function and thus requires differential calculus in locating the optimum solution. The third example (Setting Up Inventory Problem) employs repeated trials to locate optimum lot size. The examples indicate the importance of appropriate technique in the solution of specific optimization problem.

\section{Machinery Replacement/Refurbishment Model}

A machinery replacement/refurbishment model (Ekeocha, 2011) is given by

$$
\mathrm{K}(\mathrm{T})=\frac{1}{\mathrm{R}}\left[\mathrm{Q}+\mathrm{B}(\mathrm{t}) \mathrm{R}-\mathrm{S}(\mathrm{t}) \mathrm{R}^{\mathrm{t}}\right]
$$

$$
\begin{aligned}
& \mathrm{K}(\mathrm{T})=\frac{1}{\mathrm{R}}\left[\mathrm{Q}+\left(\mathrm{b}_{1}+\mathrm{b}_{2} \mathrm{t}\right) \mathrm{R}-\mathrm{Q}(1-\mathrm{d})^{\mathrm{t}} \mathrm{R}^{\mathrm{t}}\right] \\
& \text { Where } \\
& \mathrm{K}(\mathrm{T}) \quad=\text { Present value of total cost } \\
& \mathrm{B}(\mathrm{t}) \quad=\text { Time-dependent (increasing) Maintenance } \\
& \text { cost } \quad=\text { Salvage value (Deterioration and time } \\
& \mathrm{S}(\mathrm{t}) \quad \\
& \text { dependent) } \\
& \mathrm{Q} \quad=\text { Cost of machine (constant) } \\
& \mathrm{R} \quad=\text { Discount factor }\left(\frac{100}{r+100}\right) \\
& \mathrm{r} \quad=\text { Rate of return on replacement investment } \\
& \mathrm{d} \quad=\text { Deterioration rate }
\end{aligned}
$$

As usual, the objective is to find $\mathrm{T}$ that will minimize $\mathrm{K}(\mathrm{T})$. The time, $\mathrm{T}$ that gives minimum present value of total cost, $\mathrm{K}(\mathrm{T})$ corresponds to the replacement date of the machinery. Conversely, the time, $\mathrm{T}$ that produces maximum $\mathrm{K}(\mathrm{T})$ corresponds to the repair/refurbishment of the machinery.

\section{Example}

Consider a machine with the following technical details (ASA, 2000)

Name of machine:

Model:

Year of manufacture:

Cost:

Resale Value (Active Market):

Deterioration rate:

Capitalization rate:

Minor maintenance:

Major maintenance:

\section{Front-end Loader}

Y

1995

$\$ 40,000.00\left(5^{\text {th }}\right.$ year $)$
$25 \%$
$40 \%$
$\$ 2,500.00$ annually
(i) $\$ 10,000.00\left(2^{\text {nd }}\right.$ year $)$
(ii) $\$ 3,500.00\left(3^{\text {rd }}\right.$ year $)$
(iii) $\$ 6,000.00\left(4^{\text {th }}\right.$ year $)$
(iv) $\$ 20,000.00\left(5^{\text {th }}\right.$ year $)$


Solution: The tabular presentation is shown in Table 1

Table 1: Data for model Y, Front-End Loader

\begin{tabular}{|l|l|l|l|l|}
\hline $\mathrm{T}$ & $\mathrm{Q}$ & $\mathrm{b}_{1}$ & $\mathrm{~b}_{2} \mathrm{t}$ & $\mathrm{S}(\mathrm{t})$ \\
\hline 1 & 60,000 & 2500 & - & - \\
\hline 2 & 60,000 & 2500 & 10,000 & - \\
\hline 3 & 60,000 & 2500 & 3,500 & - \\
\hline 4 & 60,000 & 2500 & 6,000 & - \\
\hline 5 & 60,000 & 2500 & 20,000 & 40,000 \\
\hline 6 & 60,000 & 2500 & - & - \\
\hline 7 & 60,000 & 2500 & - & - \\
\hline
\end{tabular}

Table 2: Enumeration of Data for Hypothetical front-end Loader

\begin{tabular}{|l|l|l|l|l|l|l|l|l|l|l|l|}
\hline $\mathrm{t}$ & $\mathrm{Q}$ & $\mathrm{R}$ & $\mathrm{R}^{\mathrm{t}}$ & $\mathrm{b}_{1}$ & $\mathrm{~b}_{2} \mathrm{t}$ & $\mathrm{B}(\mathrm{t})$ & $\mathrm{B}(\mathrm{t}) \mathrm{R}$ & $\mathrm{d}$ & $\mathrm{S}(\mathrm{t})$ & $\mathrm{S}(\mathrm{t}) \mathrm{R}^{\mathrm{t}}$ & $\mathrm{K}(\mathrm{T})$ \\
\hline 1 & 60,000 & 0.71 & 0.71 & 2500 & - & 2500 & 1785 & 0.33 & - & - & 86533 \\
\hline 2 & 60,000 & 0.71 & 0.51 & 2500 & 10,000 & 12500 & 8925 & 0.50 & - & - & 96533 \\
\hline 3 & 60,000 & 0.71 & 0.36 & 2500 & 3500 & 6000 & 4284 & 0.50 & - & - & 90033 \\
\hline 4 & 60,000 & 0.71 & 0.26 & 2500 & 6000 & 8500 & 6069 & 0.83 & - & - & 92533 \\
\hline 5 & 60,000 & 0.71 & 0.19 & 2500 & 20,000 & 22500 & 16,065 & 0.83 & 40,000 & 7424 & 96136 \\
\hline 6 & 60,000 & 0.71 & 0.13 & 2500 & - & 2500 & 1785 & 0.83 & 40,000 & 5300 & $79111^{*}$ \\
\hline 7 & 60,000 & 0.71 & 0.09 & 2500 & - & 2500 & 1785 & 1.00 & 40,000 & 3784 & 81234 \\
\hline 10 & 60,000 & 0.71 & 0.03 & 2500 & - & 2500 & 1785 & 1.00 & 40,000 & 1376 & 84606 \\
\hline
\end{tabular}

Table 3:Predicted K (T) for Front-End Loader

\begin{tabular}{|l|l|l|l|l|l|l|l|l|l|}
\hline $\mathrm{T}$ & $\mathrm{Q}$ & $\mathrm{R}$ & $\mathrm{R}^{\mathrm{t}}$ & $\mathrm{B}(\mathrm{t})$ & $\mathrm{B}(\mathrm{t}) \mathrm{R}$ & $\mathrm{d}$ & $\mathrm{S}(\mathrm{t})$ & $\mathrm{S}(\mathrm{t}) \mathrm{R}^{\mathrm{t}}$ & $\mathrm{K}(\mathrm{T})$ \\
\hline 1 & 60000 & 0.71 & 0.71 & 6653.82 & 4750.83 & 0.33 & & & 89437 \\
\hline 2 & 60000 & 0.71 & 0.51 & 16653.64 & 1189.70 & 0.50 & & & 99298 \\
\hline 3 & 60000 & 0.71 & 0.36 & 10153.47 & 7249.58 & 0.50 & & & 92888 \\
\hline 4 & 60000 & 0.71 & 0.26 & 12653.29 & 9034.45 & 0.83 & & & 95353 \\
\hline 5 & 60000 & 0.71 & 0.19 & 26653.11 & 19030.32 & 0.83 & 8.52 & 1.58 & 109158 \\
\hline 6 & 60000 & 0.71 & 0.13 & 6652.93 & 4750.19 & 0.83 & 1.45 & 0.19 & $89435^{*}$ \\
\hline 7 & 60000 & 0.71 & 0.09 & 6652.75 & 4750.07 & 1.00 & 0 & 0 & 89435 \\
\hline 10 & 60000 & 0.71 & 0.03 & 6652.22 & 4749.69 & 1.00 & 0 & 0 & 89435 \\
\hline
\end{tabular}

$$
\begin{aligned}
& \text { MAINTEANCE COST REGRESSION LINE, } \\
& \mathrm{B}(\mathrm{t})=6654-0.1778 \mathrm{t} \\
& \mathrm{b}_{1}=6654 \\
& \mathrm{~b}_{2}=-0.1778 \\
& \mathrm{~b}_{2} \mathrm{t}=\text { Cost of Refurbishment in any year of refurbishment (Overhaul) }
\end{aligned}
$$

TABLE 4.: $\quad \mathrm{K}(\mathrm{T}) \quad$ against Time (Measured L and Predicted M)

\begin{tabular}{|l|l|l|l|l|l|l|l|l|}
\hline T & 1 & 2 & 3 & 4 & 5 & 6 & 7 & 8 \\
\hline K(T)L & 86533 & 96533 & 90033 & 92533 & 96136 & 79111 & 81234 & 84606 \\
\hline K(T)M & 89437 & 99298 & 92888 & 95353 & 109158 & 89435 & 89435 & 89435 \\
\hline \%Dev. & -3.24 & -2.78 & -3.07 & -2.96 & -11.93 & -11.54 & -9.17 & -5.40 \\
\hline
\end{tabular}

The percentage deviation ( $\%$ Dev.) between the measured and predicted $\mathrm{K}(\mathrm{T})$ is less than $12 \%$ which is an indication of a low error margin. 


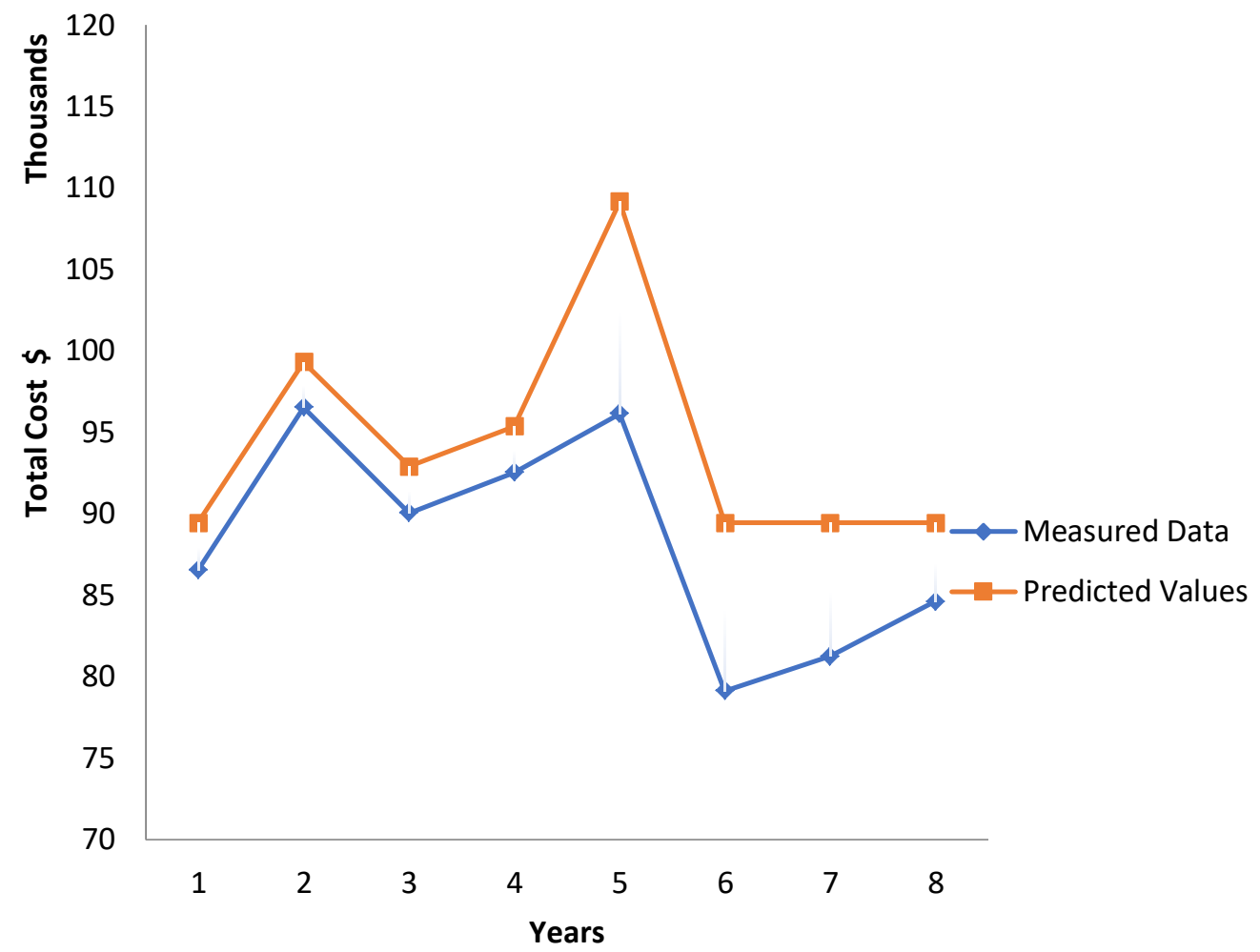

Fig.1: Comparison of the measured and predicted total cost $\mathrm{K}(\mathrm{T})$ of the Loader

The result from the tables and graph shows a replacement date of $6^{\text {th }}$ year. (Repair/Refurbishment in the $2^{\text {nd }}$ and $5^{\text {th }}$ years).

\section{Remark}

The model employs simple and straight forward solution techniques like optimization, dynamic programming and economic lot size inventory control method. The model exhibits the characteristics of overlapping subproblems and optimal substructure hence the use of these techniques for optimality. The model is calibrated with a set of data for the machine from literature while verification and comparison are performed with another set of field data from companies. The graphical presentation (fig. 1) confirms the suitability of the solution techniques.

\section{Conclusion}

Differential calculus is a suitable solution technique for the inventory model because it is a differentiable function. In some cases, repeated trials are employed in locating the optimum lot size of the inventory model. In the case of the machinery replacement/rehabilitation model, the optimization, dynamic programming and economic lot size method is suitable for optimality because the model exhibits the characteristics of overlapping subproblems and optimal substructure. In fact, the salvage value subproblem is a differentiable function like the inventory model and the differential calculus can be employed to obtain the initial replacement/rehabilitation date. Graphical presentation can also be used to complement the optimization techniques employed in the models.

Generally, it can be said that optimality is achievable for every system/model provided appropriate optimization technique is employed.

\section{References}

1. American Society of Appraisers (ASA, 2000), Valuing machinery and technical assets, Washington DC.

2. Ekeocha RJO, Odukwe AO, Agunwamba JC (2011) Machinery Replacement Problems Model, World Journal of Engineering and Pure and Applied Science, vol.1, no.3, pp. $81-87$.

3. Ekeocha, RJO. (2019) Optimization of Systems, International Journal of Sciences, 03 (2019) 117-124. DOI:10 18483/ijSci. 1964.

4. Humphreys, K.K. (1991) Jelen's Cost \& Optimization Engineering, $3^{\mathrm{RD}}$ Edition, Chapter 11, Publisher: McGraw Hill Inc. New York.

5. Merriam Webster: https://www.merriamwebster.com/dictionary/optimization.

6. Singh VP, (2009) System Modeling and Simulation, New Age International Publishers. 